University of Nebraska - Lincoln

DigitalCommons@University of Nebraska - Lincoln

Sociology Department, Faculty Publications

Sociology, Department of

2012

Does giving people their preferred survey mode actually increase survey participation rates? An Experimental Examination

\author{
Kristen Olson \\ University of Nebraska-Lincoln, kolson5@unl.edu \\ Jolene D. Smyth \\ University of Nebraska-Lincoln, jsmyth2@unl.edu \\ Heather M. Wood \\ University of Nebraska-Lincoln
}

Follow this and additional works at: https://digitalcommons.unl.edu/sociologyfacpub

Part of the Sociology Commons

Olson, Kristen; Smyth, Jolene D.; and Wood, Heather M., "Does giving people their preferred survey mode actually increase survey participation rates? An Experimental Examination" (2012). Sociology Department, Faculty Publications. 191.

https://digitalcommons.unl.edu/sociologyfacpub/191

This Article is brought to you for free and open access by the Sociology, Department of at DigitalCommons@University of Nebraska - Lincoln. It has been accepted for inclusion in Sociology Department, Faculty Publications by an authorized administrator of DigitalCommons@University of Nebraska - Lincoln. 
Published in Public Opinion Quarterly (2012); doi: 10.1093/poq/nfs024

Copyright (c) 2011 Kristen Olson, Jolene D. Smyth, and Heather M. Wood. Published by Oxford University Press on behalf of the American Association for Public Opinion Research. Used by permission.

Published online August 2, 2012.

Kristen Olson and Jolene Smyth are Assistant Professors of Sociology and Survey Research and Methodology at the University of Nebraska-Lincoln, Lincoln, NE, USA. Heather Wood is with the Department of Health and Human Services, Division of Behavioral Health, Lincoln, NE, USA. This research was conducted while Wood was a graduate student in Survey Research and Methodology at the University of Nebraska-Lincoln. A previous version of this article was presented at the Annual Meeting of the American Association for Public Opinion Research, Chicago, IL, May 13-16, 2010. The authors thank the Bureau of Sociological Research for access to the NASIS data, Dan Hoyt for support in collecting the initial mode preference questions, and three anonymous reviewers for Public Opinion Quarterly for helpful comments. This work was supported by a University of Nebraska-Lincoln Office of Research Layman Award to K. O. (PI).

\title{
Does giving people their preferred survey mode actually increase survey participation rates? An Experimental Examination
}

\author{
Kristen Olson, Jolene D. Smyth, and Heather M. Wood \\ Corresponding author - Kristen Olson, University of Nebraska-Lincoln, Department of Sociology, \\ 703 Oldfather Hall, Lincoln, NE 68588, USA; email kolson5@unl.edu
}

\begin{abstract}
Survey research has long grappled with the concept of survey mode preference: the idea that a respondent may prefer to participate in one survey mode over another. This article experimentally examines the effect of mode preference on response, contact, and cooperation rates; mode choice; and data collection efficiency. Respondents to a 2008 telephone survey ( $n=1,811$; AAPOR RR3 $=38$ percent) were asked their mode preference for future survey participation. These respondents were subsequently followed up in 2009 with two independent survey requests. The first follow-up survey request was another telephone survey $(n=548$; AAPOR RR2 $=55.5$ percent $)$. In the second follow-up survey $(n=565$; AAPOR RR $2=46.0$ percent $)$, respondents were randomly assigned to one of four mode treatments: Web only, mail only, Web followed by mail, and mail followed by Web. We find that mode preference predicts participation in Web and phone modes, cooperation in phone mode (where contact and cooperation can be disentangled), and the selection of a mode when given the option of two modes. We find weak and mixed evidence about the relationship between mode preference and reduction of field effort. We discuss the important implications these findings have for mixed mode surveys.
\end{abstract}




\section{Introduction}

As survey response rates decline and costs increase (Curtin, Presser, and Singer 2000; de Leeuw and de Heer 2002), survey organizations are increasingly turning to mixed mode survey designs. A mixed mode survey design is one in which two or more modes are offered to sampled units to recruit respondents and measure their responses (de Leeuw 2005; Dillman, Smyth, and Christian 2009). One hypothesis for differences in response rates across face-to-face, telephone, mail, and Web modes is that people have positive attitudes toward certain modes and neutral or negative attitudes toward other modes; that is, a mode preference (Groves and Kahn 1979). This belief in mode preferences has fueled a related hypothesis that has gained considerable traction in the field - that catering to sample members' mode preferences by using mixed mode designs will increase the likelihood that they will respond, resulting in higher response rates (Dillman and Tarnai 1988; Schaefer and Dillman 1998; Shih and Fan 2002). Despite this long-standing hypothesis, little empirical research has evaluated whether voiced mode preferences actually increase participation rates in the preferred mode versus a non-preferred mode. Furthermore, the role that mode preference plays in other survey outcomes, including mode choice in multi-mode studies, timing of participation, and level of effort needed to obtain participation, is unexplored. To address these gaps, this article will empirically examine the following questions:

1. Does mode preference predict response, contact, and cooperation rates in single mode and mixed mode survey designs?

2. Is the relationship between mode preference and response, contact, and cooperation rates due to sample composition differences?

3. Does mode preference predict the mode respondents select when given a choice of modes?

4. Does catering to a sampled person's mode preference speed up survey participation and reduce the time and effort needed to recruit sample members?

\section{Literature Review}

Most respondents, when asked whether they would prefer to answer survey questions in person, on the telephone, by mail, or by Web, report a mode preference. We refer to "mode preference" as a positive view toward participating in a particular mode rather than "mode choice," the mode one selects when given multiple options (Dillman et al. 2009; Dillman, West, and Clark 1994; Levenstein 2009; Shih and Fan 2002). Respondents express their preference to participate in face-to-face interviews (Groves and 
Kahn 1979), telephone surveys (Smyth, Olson, and Richards 2009), mail surveys (Gilbert 2009; Levenstein 2009; Millar, O'Neill, and Dillman 2009; Miller et al. 2002; Tarnai and Paxson 2004), and Web surveys (Gilbert 2009; Miller et al. 2002; Ryan et al. 2002; Tarnai and Paxson 2004). In general, respondents endorse the mode in which they are participating at far greater rates than other modes (Gesell, Drain, and Sullivan 2007; Groves and Kahn 1979; Millar, O’Neill, and Dillman 2009; Miller et al. 2002; Tarnai and Paxson 2004).

Little published research examines whether voiced mode preferences predict participation behaviors. Part of the difficulty in evaluating the relationship between mode preference and participation is that a multi-step approach is needed. Mode preferences must be measured first on a set of persons in at least one mode. Then, participants in the first study must be followed up with a subsequent survey request with experimentally offered variation in modes for participation. Although some studies using a variation of this design show differences in response rates for those who receive their preferred mode versus not receiving their preferred mode (Gilbert 2009; NSF 2008), others show little effect of being offered a preferred mode (Levenstein 2009). Moreover, almost all of the existing work has been conducted on special populations, including college graduates (Gilbert 2009), doctoral recipients (NSF 2008; Selfa and Sederstrom 2006), and U.S. Army members (Levenstein 2009). In sum, there is no clear evidence that mode preference predicts survey participation in these special populations.

Two theoretical frameworks predict that offering a sampled person's preferred mode will increase response rates in that mode. First, leverage-saliency theory (Groves, Singer, and Corning 2000) argues that people view positively certain design features (i.e., positive leverage) and are neutral or negative on other design features. Mode preference is a voiced attitude for a design feature toward which the respondent has positive leverage, and thus the sampled person should be more likely to participate when offered that mode. Alternatively, social exchange theory posits that respondents will be more likely to participate in a survey if their costs are minimized, the benefits to them are maximized, and they trust that the benefits will come to fruition (Dillman, Smyth, and Christian 2009). Providing respondents with their preferred mode is thought to decrease costs to the respondent by making it as easy and convenient as possible for them to respond and perhaps increase benefits from participating in a mode that they view positively. In both theoretical frameworks, making salient a preferred mode, minimizing costs, and increasing benefits are expected to influence cooperation rates rather than affecting contact rates. Interestingly, the theories are silent on whether the ordering of the modes offered to the respondent matters - that is, whether the perceived benefits or positive leverage of a preferred mode hold when it is not offered up front, as in a sequential mixed mode design. Previous research has shown that the effectiveness of initially offered design features on increasing the response rate wear off over the course 
of the data-collection period (Olson and Groves forthcoming). Thus, we obtain our first hypothesis:

H1: Sampled persons who receive their preferred mode will participate at higher rates than sampled persons who do not receive their preferred mode, especially if it is the first mode offered. This increase will come because of an increase in cooperation rates, not contact rates.

Mode preference is sometimes discussed in terms of certain demographic groups preferring one mode over another. In particular, young persons are hypothesized to prefer Web modes (Diment and Garrett-Jones 2007; Kaplowitz, Hadlock, and Levine 2004; Millar and Dillman 2011; Vehovar et al. 2002), with mixed predictions about preference for interviewer-administered and mail modes (Denniston et al. 2000). Only two unpublished studies of which we are aware have examined who actually reports preferring what mode, and found evidence that older persons and persons with poor computer skills prefer nonWeb modes, but not clear evidence that younger persons necessarily prefer the Web (Millar, O’Neill, and Dillman 2009; Smyth, Olson, and Richards 2009). As such, we come to our second hypothesis:

H2: If mode preferences are real, mode preference will continue to positively predict response and cooperation after accounting for sample person characteristics. Sample composition differences will account for any observed differences in contact rates for persons who prefer different modes.

If mode preference is meaningful, then it should also predict the mode that sampled persons select when given a choice between modes (Dillman, West, and Clark 1994; Diment and Garrett-Jones 2007; Millar and Dillman 2011; Tarnai and Paxson 2004). Persons who prefer a Web mode, for example, should select the Web when offered a choice between mail and Web modes. Most of the mode choice literature does not explicitly measure mode preference, but instead derives mode preferences from demographic characteristics (Diment and Garrett-Jones 2007; Kaplowitz, Hadlock, and Levine 2004; Shih and Fan 2002). In one of the few studies that pre-measured mode preference, Levenstein (2009) found that persons who voiced a prior preference for a Web mode were more likely to select it than people who had voiced a prior preference for a mail mode. In addition, if mode preferences are real, then switching modes from a non-preferred mode to a preferred mode, as in a sequential mixed mode design, should increase response rates because individuals choose to participate in their preferred mode. Our third hypothesis is thus: 
H3: In a mixed mode design, persons who are offered their preferred mode and a non-preferred mode will be more likely to select the preferred mode in which to participate. In a sequential mixed mode design, persons who prefer the second mode will be more likely to participate after the mode switch than before the mode switch.

If mode preference improves response rates, it may also improve the efficiency of data collection (Shih and Fan 2002). In particular, if sample members participate faster (fewer days in the field) or with less effort exerted (fewer follow-up attempts) when offered their preferred mode, then catering to mode preference may reduce survey costs. In a sequential mixed mode design, however, offering a preferred mode later may increase the time to completion. The one study of which we are aware that explicitly evaluates mode preference as a reported attitude and effort shows no clear evidence of savings in effort or reduction in field time by offering a person his or her preferred mode (Selfa and Sederstrom 2006), but this study did not separate the measurement of mode preference from the survey in which effort was being measured. Our final hypothesis is as follows:

H4: In single mode studies, persons who receive their preferred mode will participate faster and with fewer follow-up attempts than those who do not receive their preferred mode. In mixed mode studies, persons who receive their preferred mode first will participate faster and with fewer follow-up attempts than those who do not receive their preferred mode first.

\section{Data}

The data for this study come from a series of three surveys. The first survey measures mode preference for a set of respondents; the second two surveys follow up with the same respondents and evaluate whether the previously reported mode preference predicts participation in that mode. Two of the studies were conducted by the Bureau of Sociological Research (BOSR) at the University of Nebraska-Lincoln; the final study was an experiment designed and implemented by the authors.

The first study is the 2008 Nebraska Annual Social Indicators Survey (2008 NASIS). Between February and August 2008, an RDD sample of 1,811 households with adults aged nineteen and older with listed telephone numbers in Nebraska were interviewed (AAPOR RR3 = 38 percent). One adult was randomly selected from each household using the age position in the household (e.g., oldest, second oldest, youngest). At the end of the survey, respondents were asked if they would be willing to participate in future "social research projects," and 1,370 (75.7 percent) indicated their willingness. 
Two independent follow-up surveys of these respondents were conducted one year later. The first follow-up was conducted by CATI in the 2009 Nebraska Annual Social Indicators Survey (2009 NASIS) by the BOSR between March and July 2009. A simple random sample of $n=1,000$ of the 1,370 individuals who had participated in the 2008 NASIS and stated their willingness for future participation were included in the 2009 NASIS. The name (if available), sex, and year of birth of the 2008 NASIS respondent were used to identify the appropriate respondent in each household who had previously participated. ${ }^{1}$ Overall, 555 of the $n=1,000$ sampled persons participated in the 2009 NASIS, with a response rate of 55.5 percent (AAPOR RR2). We will call this data collection the "Phone Only treatment."

The second follow-up was a mode experiment designed and implemented by the authors. In this study, the Quality of Life in a Changing Nebraska survey (QLCN), all $n=$ 1,370 respondents who were willing to be included in future social research projects were considered eligible for the experiment. We randomly assigned these cases to one of four mode conditions varying in whether it was a single mode or mixed mode design, and among the mixed mode designs, varying the order in which they received mail or Web modes. The single mode designs in the QLCN were Mail Only and Web Only, and the sequential mixed mode designs were Mail with a Web follow-up (Mail then Web), and Web with a Mail follow-up (Web then Mail). We selected a sequential mixed mode design to isolate whether mode preferences are salient when sampled persons are first offered a different, non-preferred mode and then switched to their preferred mode. We identified sample persons with adequate information for mailing addresses, reducing the eligible sample size to $n=1,229$. This study was conducted from July 2009 (immediately after the completion of the 2009 NASIS) through October 2009.

The overall design strategy was to make the mail and Web questionnaires and recruitment protocols as similar in both content and appearance as possible to minimize unintentional design differences across the modes. A standard five-mailing protocol was used for all respondents (Dillman, Smyth, and Christian 2009), regardless of their assigned experimental treatment. First, a pre-notification letter was sent to all households via postal mail with a first-class stamped envelope, alerting them to the forthcoming questionnaire. No information was provided in the pre-notification letter about the mode of data collection. Three days later, the questionnaire or invitation to participate in the survey was sent to all households. A random half of the sample received a cover letter with a four-page questionnaire entitled the "Quality of Life in a Changing Nebraska" survey and a business-reply return envelope. The other random half of the sample received a cover letter containing information about how to access the Web survey (the website and their personal Web

1. The 2009 NASIS also included an RDD sample of listed telephone numbers, fielded at the same time and by the same interviewers. Analyses in this article are limited to the cases originating in the 2008 NASIS. 
ID number) for the QLCN. Since names were not available for all sample members, sex and age rank in the household (e.g., youngest male, oldest female) were used to identify the relevant individual. One week later, a postcard reminder was sent to nonrespondents, encouraging them to complete the questionnaire. The mail nonrespondents were asked to mail back their questionnaire; the Web nonrespondents received the Web address and their ID for accessing the survey.

Two weeks after the reminder postcard was sent, a random half of all nonrespondents in each mode was switched to the other mode. That is, half of the mail nonrespondents were followed up with a replacement mail questionnaire; the remaining half were provided with the website and their ID for accessing the survey online. Similarly, half of the Web nonrespondents were followed up with a mail questionnaire, offered explicitly for the first time to this group, and the other half were followed up with a replacement letter again informing them of the website and their ID. Three weeks later, a thank-you letter was sent to all sample members, intending to act as a final prompt for questionnaire completion. Overall, 565 respondents participated in the QLCN, with three partial completes (AAPOR RR2 $=46.0$ percent).

Overall, there is no statistical difference in response rates across three of the four selfadministered treatments. Response rates in the Mail Only, Mail then Web, and Web then Mail treatments range from 50.0 (Mail then Web) to 53.8 percent (Mail Only) $\left(X^{2}(2)=\right.$ $1.07, p=0.58)$. The response rate in the Web Only treatment (25.4 percent) is significantly different $(p<.0001)$ from the other self-administered treatments.

Although none of the recruitment materials indicated that an alternative mode was available, requests for an alternative mode were accommodated (limited to Web and mail). None of the persons assigned to the mail conditions asked for a Web survey, but many sampled persons (reported below) in the Web conditions asked for and were sent a mail survey.

\section{Methods}

\section{Defining Mode Preference}

During the 2008 NASIS, respondents were asked, "If you received a request to do another survey like this one, would you prefer to participate in an in-person interview at your home, an interview on your home phone, an interview on your cell phone, a paper survey sent by mail, or a survey on the Internet?" Almost half (49.2 percent) of the respondents reported preferring to be interviewed on their home phone, 24.6 percent preferred a mail survey, 19.7 percent preferred a Web survey, and 4.5 percent said that they don't know or refused to give a mode preference. Because few respondents preferred an in-person (1.7 percent) or a cell-phone interview ( 0.4 percent), we combined these mode 
preferences with home phone interview into an "interviewer-administered survey" mode preference category (51.3 percent).

The follow-up surveys use both single mode and mixed mode treatments. For the single mode treatments, determining whether the sampled person was offered their "preferred mode" is straightforward, but for the mixed mode treatments it is more complex. Table 1 summarizes how we operationalize having been explicitly offered one's preferred mode for each of the treatments in the follow-up surveys. In the Phone Only treatment, any person who voiced a prior preference for interviewer-administered modes is designated as receiving their "preferred mode" (56.2 percent of those selected for the phone mode), whereas those whose prior preference was for mail or Web surveys are designated as not receiving their preferred mode. Similarly, in the Mail Only and Web Only treatments, those who voiced a preference for mail or Web surveys, respectively, are assigned as receiving their preferred mode (23.9 percent of the Mail Only treatment and 20.6 percent of the Web Only treatment).

For the sequential mixed mode surveys, we use the first mode the sampled persons were offered to define whether they received their preferred mode. In the Mail then Web treatment, persons who previously voiced a preference for a mail survey were designated as receiving their "preferred mode" (16.2 percent), whereas those who voiced a preference for interviewer-administered or Web surveys were assigned as not receiving their preferred mode. Conversely, in the Web then Mail treatment, those who previously voiced a Web preference are assigned as receiving their "preferred mode" (23.6 percent).

\section{Analysis Methods}

This analysis examines the relationship between reported mode preference from the 2008 NASIS and survey participation in the 2009 NASIS and QLCN. We use AAPOR RR2 (AAPOR 2011) for all response rate calculations.

Table 1. Mode Preference Assignment by Mode Treatment and Expected Mode Preference

\begin{tabular}{|c|c|c|c|c|}
\hline \multirow[b]{2}{*}{$\begin{array}{l}\text { Mode Treatment } \\
\text { Assigned }\end{array}$} & \multirow[b]{2}{*}{$\begin{array}{l}\text { Interviewer- } \\
\text { Administered }\end{array}$} & \multicolumn{3}{|c|}{ Voiced preference for... } \\
\hline & & Mail & Web & $\begin{array}{l}\% \text { Received } \\
\text { Preferred Mode }\end{array}$ \\
\hline \multicolumn{5}{|l|}{ Single Mode } \\
\hline Phone Only & Preferred & Not preferred & Not preferred & 56.2 \\
\hline Mail Only & Not preferred & Preferred & Not preferred & 23.9 \\
\hline Web Only & Not preferred & Not preferred & Preferred & 20.6 \\
\hline \multicolumn{5}{|c|}{ Sequential Mixed Mode } \\
\hline Mail then Web & Not preferred & Preferred & Not preferred & 16.2 \\
\hline Web then Mail & Not preferred & Not preferred & Preferred & 23.6 \\
\hline
\end{tabular}


Because the 2009 NASIS was conducted via CATI, we can disentangle noncontacts from refusals, allowing us to also examine the relationship between reported mode preference and contact and cooperation. ${ }^{2}$ As this is a panel study, noncontacts include nonlocated sample members (i.e., those for whom a current or working telephone number could not be found or confirmed), consisting of $n=150$ of the 1,000 sampled telephone numbers. Contact is defined as any household where an interview, refusal, appointment, or other contact with the household was made (AAPOR CON1 = 74.1 percent). Cooperation is defined as a completed or partial interview with the 2008 NASIS respondent, conditional on successful contact (AAPOR COOP2 $=74.9$ percent). All classifications follow disposition codes defined by the AAPOR Standard Definitions (AAPOR 2011).

We start with bivariate analyses to examine whether there is an association between mode preference voiced in the 2008 NASIS and response rates in the 2009 NASIS and the QLCN, followed by contact and cooperation rates in the 2009 NASIS. Multivariate logistic regression models are then used to predict response, contact, and cooperation. Because mode preferences are not randomly assigned to sample persons, a relationship between mode preference and participation may simply reflect sample composition differences. As such, we examine whether characteristics previously found to predict mode preference (Millar, O’Neill, and Dillman 2009; Smyth, Olson, and Richards 2009) mediate the relationship between mode preference and response, contact, and cooperation (see the appendix for full question wording and Table 2 for descriptive statistics). We also test whether there is an interaction effect between mode preference and mode of administration.

We then examine whether the level of effort required to recruit respondents differs over mode preference groups. We focus on the mean number of days in the field for all cases and only for interviewed cases. We also examine effort in the QLCN before and after the second questionnaire mailing, the main source of variability in level of effort across cases, in which the official mode switch occurred for persons in the mixed mode treatments.

Item-missing data are multiply imputed five times using sequential regression imputation in IVEWARE (Raghunathan et al. 2001). Both follow-up surveys are analyzed simultaneously. Overall, 903 persons were in both the 2009 NASIS and the QLCN, and 326 persons were included in only one of these studies, for a total of 1,329 of the 1,370 willing persons followed up in at least one of the two studies. All analyses account for multiple imputation and, where appropriate, clustering of repeated survey requests within sampled persons through complex survey design analyses in SAS-callable IVEWare with sampled persons as the cluster. 
Table 2. Descriptive Statistics and Standard Errors, NASIS 2009 and QLCN (standard errors adjusted for multiple imputation and clustering of requests within respondents)

\begin{tabular}{|c|c|c|}
\hline & Mean or Percent & Std. Err. \\
\hline Mean age in years & 53.56 & $(0.44)$ \\
\hline \multicolumn{3}{|l|}{ Education } \\
\hline Graduate degree & $13.6 \%$ & $(1.0 \%)$ \\
\hline Bachelor's degree & $26.0 \%$ & $(1.3 \%)$ \\
\hline Some college or associate's degree & $28.7 \%$ & $(1.3 \%)$ \\
\hline High school degree or less & $31.7 \%$ & $(2.0 \%)$ \\
\hline Female & $58.3 \%$ & $(1.4 \%)$ \\
\hline Has kids under age 18 & $36.9 \%$ & $(1.4 \%)$ \\
\hline \multicolumn{3}{|l|}{ Marital status } \\
\hline Never married & $10.0 \%$ & $(0.9 \%)$ \\
\hline Not married & $23.2 \%$ & $(1.2 \%)$ \\
\hline Married & $66.8 \%$ & $(1.5 \%)$ \\
\hline Employed & $71.8 \%$ & $(1.3 \%)$ \\
\hline \multicolumn{3}{|l|}{ Income } \\
\hline$<\$ 20,000$ & $12.0 \%$ & $(1.0 \%)$ \\
\hline$\$ 20,000-40,000$ & $22.2 \%$ & $(1.3 \%)$ \\
\hline$\$ 40,000-60,000$ & $23.4 \%$ & $(1.2 \%)$ \\
\hline$\$ 60,000+$ & $42.4 \%$ & $(1.9 \%)$ \\
\hline Has Internet access & $86.5 \%$ & $(1.0 \%)$ \\
\hline Has a cell phone & $86.2 \%$ & $(1.0 \%)$ \\
\hline Live in a city & $81.4 \%$ & $(1.1 \%)$ \\
\hline Excellent or good self-rated computer ability & $54.0 \%$ & $(1.4 \%)$ \\
\hline \multicolumn{3}{|l|}{ Self-rated hearing } \\
\hline Poor & $6.0 \%$ & $(0.7 \%)$ \\
\hline Fair & $18.9 \%$ & $(1.1 \%)$ \\
\hline Good & $45.3 \%$ & $(1.4 \%)$ \\
\hline Excellent & $29.9 \%$ & $(1.9 \%)$ \\
\hline \multicolumn{3}{|l|}{ Self-rated health } \\
\hline Poor & $2.2 \%$ & $(0.4 \%)$ \\
\hline Fair & $15.7 \%$ & $(1.0 \%)$ \\
\hline Good & $51.3 \%$ & $(1.4 \%)$ \\
\hline Excellent & $30.9 \%$ & $(1.8 \%)$ \\
\hline \multicolumn{3}{|l|}{ Concerned about ID theft } \\
\hline Never & $5.0 \%$ & $(0.6 \%)$ \\
\hline Rarely & $19.3 \%$ & $(1.1 \%)$ \\
\hline Sometimes & $41.1 \%$ & $(1.4 \%)$ \\
\hline Often & $25.7 \%$ & $(1.2 \%)$ \\
\hline Almost always & $9.0 \%$ & $(2.2 \%)$ \\
\hline High CESD score & $24.5 \%$ & $(1.2 \%)$ \\
\hline
\end{tabular}




\section{Results}

Hypothesis 1: Mode Preference and Response Rates. In H1, we hypothesize that persons who receive their preferred mode will be more likely to participate than those who do not receive their preferred mode. Figure 1 shows that in the Web Only and Phone Only treatments, those who received their preferred mode have significantly higher response rates than those who did not receive their preferred mode. In the Web Only treatment, the response rate among those who previously reported preferring Web surveys is 40 percent, compared to 21.6 percent for those who previously reported a preference that was not the Web mode $(t=2.94, p<.01)$. In the Phone Only treatment, those who prefer surveys on their home phones or other interviewer-administered surveys have a response rate of 60.3 percent, compared to 49.3 percent for those who do not prefer interviewer-administered surveys $(t=3.49, p<.0001)$. The trend is in the correct direction in the Mail Only treatment, but the response rate for those who prefer mail surveys ( 57.7 percent) is not statistically different from the rate for those who prefer other modes (52.7 percent) $(t=0.75$, n.s.).

The mixed mode experimental conditions show no difference in response rates between those who are offered their preferred modes as the initial mode and those who are not (see figure 1). In the Mail then Web treatment, 52.9 percent of those who voiced a preference for mail surveys participated, compared to 49.4 percent of those who preferred other modes $(t=0.46$, n.s.). In the Web then Mail treatment, the pattern reverses, with

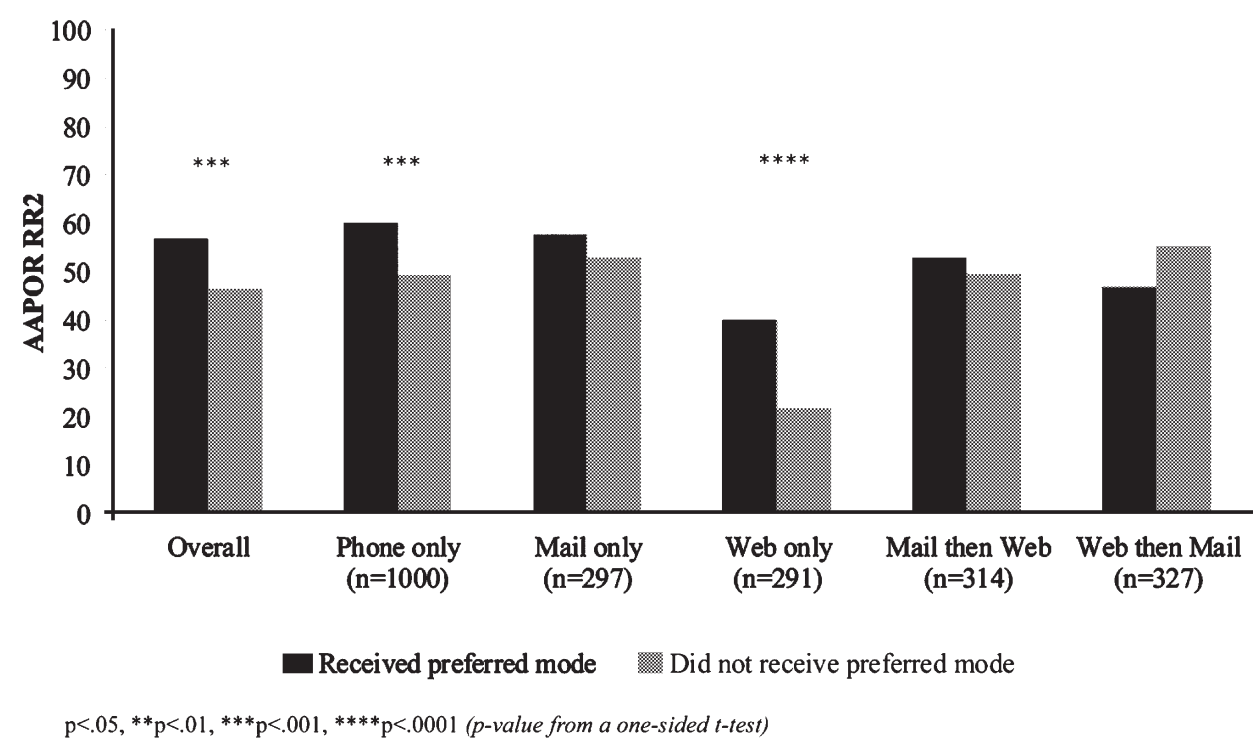

Figure 1. AAPOR Response Rate 2 by Mode Preference for Five Treatments, NASIS 2009 and QLCN. 
46.8 percent of those who preferred the Web mode participating versus 55.2 percent of those who preferred other modes $(t=1.30$, n.s.). Thus, we find support for H1 in the single mode designs, but not in the mixed mode designs.

Additionally, we hypothesize that mode preference will positively affect cooperation but will not be associated with contactability. We can only disentangle contact from cooperation in the telephone treatment. Whereas contact rates are only marginally higher in the Phone Only treatment for those who reported preferring interviewer-administered surveys (contact rate of 76.2 percent) compared to those who preferred other survey modes (71.5 percent) $(t=21.67, p<0.10)$, cooperation rates are significantly higher for those who received their preferred mode. Roughly 79 percent of those who preferred intervieweradministered modes cooperated, compared to 69.0 percent of those who preferred other modes, a ten-percentage-point difference $(t=23.18, p<.001)$. We thus have strong support for our hypothesis that mode preference predicts cooperation rates rather than contact rates, at least in the phone survey.

Hypothesis 2: Sample Composition Differences. We now turn to the hypothesis that mode preference will continue to predict response and cooperation after accounting for sample composition differences (e.g., familiarity with the Internet, sex, age) in who prefers each mode (H2). As we can see in Table 3, those who were offered their preferred mode are significantly more likely to respond than participants who were not offered their preferred mode (model $1: B=0.323, S E=0.090, p<.001$ ). This pattern for mode preference having higher response rates holds after accounting for demographic and other characteristics (model 3). Thus, mode preference has an effect on response rates overall.

The models also examine differences in response rates across modes and whether the effect of mode preference differs across the five mode treatments. The Web Only treatment has the lowest response rate overall (model 1: $B=21.187, S E=0.148, p<$ $.0001)$, with the response rates in the other modes not statistically differing $(p>.05)$ from the Phone Only treatment. This difference holds with the addition of demographic and other characteristics. The strength of the effect of mode preference is significantly lower in the Web then Mail treatment $(B=20.785, S E=0.297, p<.01)$ compared to the Phone Only treatment, but this difference disappears once demographic characteristics are included.

We now examine whether the relationships between mode preference, contactability, and cooperation in the phone survey can be attributed to characteristics of those who prefer the telephone (Table 4). When demographic and other characteristics are taken into account, there is clearly no difference in contactability between those who prefer the telephone and those who prefer a different mode $(B=0.082, S E=0.160$, n.s.). That is, any observed differences in contact rates across these mode preference groups are due to differences in sample composition. 
Table 3. Logistic Regression Coefficients and Standard Errors Predicting Overall Survey Participation, NASIS 2009 and QLCN (standard errors adjusted for multiple imputation and clustering of requests within respondents)

\begin{tabular}{|c|c|c|c|c|c|c|}
\hline & \multicolumn{2}{|c|}{ Model $1(n=1,329)$} & \multicolumn{2}{|c|}{ Model $2(n=1,329)$} & \multicolumn{2}{|c|}{ Model $3(n=1,329)$} \\
\hline & B & SE & B & SE & B & SE \\
\hline Intercept & 0.041 & $(0.080)$ & 20.027 & $(0.096)$ & $-2.471^{\star * \star *}$ & $(0.558)$ \\
\hline \multicolumn{7}{|l|}{ Mode preference } \\
\hline Preferred mode & $0.323^{* * *}$ & $(0.090)$ & $0.446^{\star \star *}$ & $(0.129)$ & $0.347^{*}$ & $(0.137)$ \\
\hline Not preferred mode & - & & - & & - & \\
\hline \multicolumn{7}{|l|}{ Mode treatment } \\
\hline Mail only & 0.038 & $(0.129)$ & 0.134 & $(0.162)$ & 0.042 & $(0.171)$ \\
\hline Web only & $-1.187^{\star * * *}$ & $(0.148)$ & $-1.259^{\star * \star *}$ & $(0.185)$ & $-1.449^{\star * * *}$ & $(0.192)$ \\
\hline Mail web & -0.093 & $(0.127)$ & 0.005 & $(0.154)$ & -0.056 & $(0.162)$ \\
\hline Web mail & 0.013 & $(0.128)$ & 0.236 & $(0.156)$ & 0.098 & $(0.165)$ \\
\hline Phone & - & & - & & - & \\
\hline \multicolumn{7}{|c|}{ Mode preference * mode treatment } \\
\hline Mail only *Preferred mode & & & -0.240 & $(0.319)$ & -0.046 & $(0.331)$ \\
\hline Web only *Preferred mode & & & 0.435 & $(0.342)$ & 0.710 & $(0.367)$ \\
\hline Mail Web *Preferred mode & & & -0.306 & $(0.350)$ & -0.147 & $(0.358)$ \\
\hline Web mail *Preferred mode & & & $-0.785^{\star *}$ & $(0.297)$ & -0.541 & $(0.308)$ \\
\hline Age (continuous) & & & & & $0.028^{* * * *}$ & $(0.005)$ \\
\hline \multicolumn{7}{|l|}{ Education } \\
\hline Graduate degree & & & & & $0.558^{\star * *}$ & $(0.172)$ \\
\hline Bachelor's degree & & & & & 0.247 & $(0.146)$ \\
\hline Some college or AA & & & & & 0.131 & $(0.135)$ \\
\hline High school & & & & & - & \\
\hline \multicolumn{7}{|l|}{ Gender } \\
\hline Female & & & & & $0.290^{*}$ & $(0.110)$ \\
\hline Male & & & & & - & \\
\hline \multicolumn{7}{|l|}{ Children under age 18} \\
\hline Any kids under age 18 & & & & & -0.191 & $(0.130)$ \\
\hline No kids under age 18 & & & & & - & \\
\hline \multicolumn{7}{|l|}{ Marital status } \\
\hline Never married & & & & & -0.006 & $(0.200)$ \\
\hline Not married & & & & & -0.198 & $(0.144)$ \\
\hline Married & & & & & - & \\
\hline \multicolumn{7}{|l|}{ Employment status } \\
\hline Employed & & & & & 0.005 & $(0.132)$ \\
\hline Not employed & & & & & - & \\
\hline
\end{tabular}


Table 3. Continued

\begin{tabular}{|c|c|c|c|c|c|c|}
\hline & \multicolumn{2}{|c|}{ Model $1(n=1,329)$} & \multicolumn{2}{|c|}{ Model $2(n=1,329)$} & \multicolumn{2}{|c|}{ Model $3(n=1,329)$} \\
\hline & B & SE & B & SE & B & SE \\
\hline \multicolumn{7}{|l|}{ Income } \\
\hline$<\$ 20 \mathrm{~K}$ & & & & & -0.171 & $(0.219)$ \\
\hline$\$ 20 \mathrm{~K}-40 \mathrm{~K}$ & & & & & 0.130 & $(0.157)$ \\
\hline$\$ 40 \mathrm{~K}-60 \mathrm{~K}$ & & & & & 0.157 & $(0.138)$ \\
\hline$>\$ 60 \mathrm{~K}$ & & & & & - & \\
\hline \multicolumn{7}{|l|}{ Internet access } \\
\hline Have Internet access & & & & & $0.460^{*}$ & $(0.180)$ \\
\hline No Internet access & & & & & - & \\
\hline \multicolumn{7}{|l|}{ Cell phone } \\
\hline Have a cell phone & & & & & 0.172 & $(0.168)$ \\
\hline No cell phone & & & & & - & \\
\hline \multicolumn{7}{|l|}{ Urbanicity } \\
\hline Live in a city & & & & & -0.055 & $(0.130)$ \\
\hline Live in a farm or open country & & & & & - & \\
\hline \multicolumn{7}{|l|}{ Self-rated computer ability } \\
\hline Excellent or good & & & & & 0.046 & $(0.116)$ \\
\hline Fair or poor & & & & & - & \\
\hline \multicolumn{7}{|l|}{ Self-rated hearing } \\
\hline (1 = poor, 4 = excellent $)$ & & & & & -0.050 & $(0.067)$ \\
\hline \multicolumn{7}{|l|}{ Self-rated health } \\
\hline ( 1 = poor, 4 = excellent $)$ & & & & & $0.172^{*}$ & $(0.077)$ \\
\hline \multicolumn{7}{|l|}{ Concerned about } \\
\hline \multicolumn{7}{|l|}{ identity theft } \\
\hline ( $1=$ never, $5=$ almost always $)$ & & & & & -0.043 & $(0.052)$ \\
\hline \multicolumn{7}{|l|}{ Depression } \\
\hline High CESD score & & & & & -0.071 & $(0.124)$ \\
\hline \multicolumn{7}{|l|}{ Low CESD score } \\
\hline & & & & & - & \\
\hline Pseudo $R^{2}$ & $3.2 \%$ & & $3.6 \%$ & & $7.7 \%$ & \\
\hline -2 Log likelihood & 2990.04 & & 2978.95 & & 2848.66 & \\
\hline \multicolumn{7}{|l|}{ Change in $-2 L L$ from } \\
\hline previous model & & & 11.09 & & 130.29 & \\
\hline
\end{tabular}

${ }^{*} p<.05 ;{ }^{* *} p<.01 ;{ }^{* * *} p<.001 ;{ }^{* * *} p<.0001$

Unlike the differences in contact rates, the differences in cooperation rates between those who prefer the phone and those who prefer another mode do not go away with demographic controls. There are clear differences in cooperation rates in a telephone survey between these two groups $(B=0.538, S E=0.190, p<.01)$. Thus, we have strong support for our hypothesis that mode preference will continue to predict response and cooperation rates. Importantly, we have also explained away the marginally significant association be- 
tween contact rates and mode preference with the included sample composition variables, providing further support for $\mathrm{H} 1$.

Hypothesis 3: Mode Preference and Mode Choice. The next hypothesis we examine is whether individuals choose their preferred mode when two modes are available (H3). Here, we focus only on the self-administered treatments (Table 5). In the single mode treatments (Mail Only and Web Only), only one mode is explicitly offered to the sample person. Yet, if a sampled person called in and asked for an alternative mode, we allowed those persons to participate in that mode. All of the persons in the Mail Only treatment participated by mail (that is, no one asked for a Web survey), and 81 percent in the Web Only treatment participated by Web, with 19 percent asking for a mail survey. In the mixed mode treatments, the order in which modes are offered matters. Just under 3 percent of respondents in the Mail then Web treatment participated by Web, compared to 36 percent of respondents in the Web then Mail treatment.

In general, people who preferred Web surveys are more likely than others to participate via the Web (Table 4). All of the respondents (100.0 percent) who preferred Web and were assigned to the Web Only treatment participated in that mode, compared to only 76.9 percent of those who stated that they preferred mail and 68.5 percent of those who preferred phone $\left(\chi^{2}(2)=9.11, p<.01\right)$. In the mixed mode treatments, sample persons had an explicit, although sequential, choice of modes. Among persons assigned to the Mail then Web treatment, 4.3 percent of those who preferred Web participated in the Web survey, compared to 3.7 percent of those who preferred mail and 1.9 percent of those who preferred phone. Thus, the pattern is in the expected direction; however, there is no statistical association between mode preference and mode choice in this group $\left(\chi^{2}(2)=0.63, p=\right.$ $.73)$, perhaps because of small sample sizes. Among those assigned to the Web then Mail treatment, 55.6 percent who preferred Web participated by Web, compared to 36.1 percent who preferred mail and 29.7 percent who preferred phone $\left(\chi^{2}(2)=7.66, p<.02\right)$.

It is possible that the higher incidence of responding by Web among those who prefer Web occurs because they are more likely to have Internet access than those who reported other mode preferences. When we limit our analysis to only those with Internet access, the pattern of those who prefer Web being more likely to respond by Web holds, although the magnitude of the differences is somewhat attenuated (bottom panel of Table 5).

Hypothesis 4: Mode Preference and Recruitment Effort. The final hypothesis is that those who received their preferred mode participate faster and with fewer follow-up attempts than those who did not receive that mode $(\mathrm{H} 4)$.

In the Mail Only treatment, there is no association between mode preferences and timing of participation, whether we examine rates of participation before versus after the mode switch $\left(\chi^{2}(2)=1.12, p=0.57\right.$; Figure 2 ) or the number of days in the field before completion (an average of 15.7 days before completion for those who preferred mail compared to 15.4 days for those who did not prefer mail, $t=0.12$, n.s.). In contrast, in the Web 


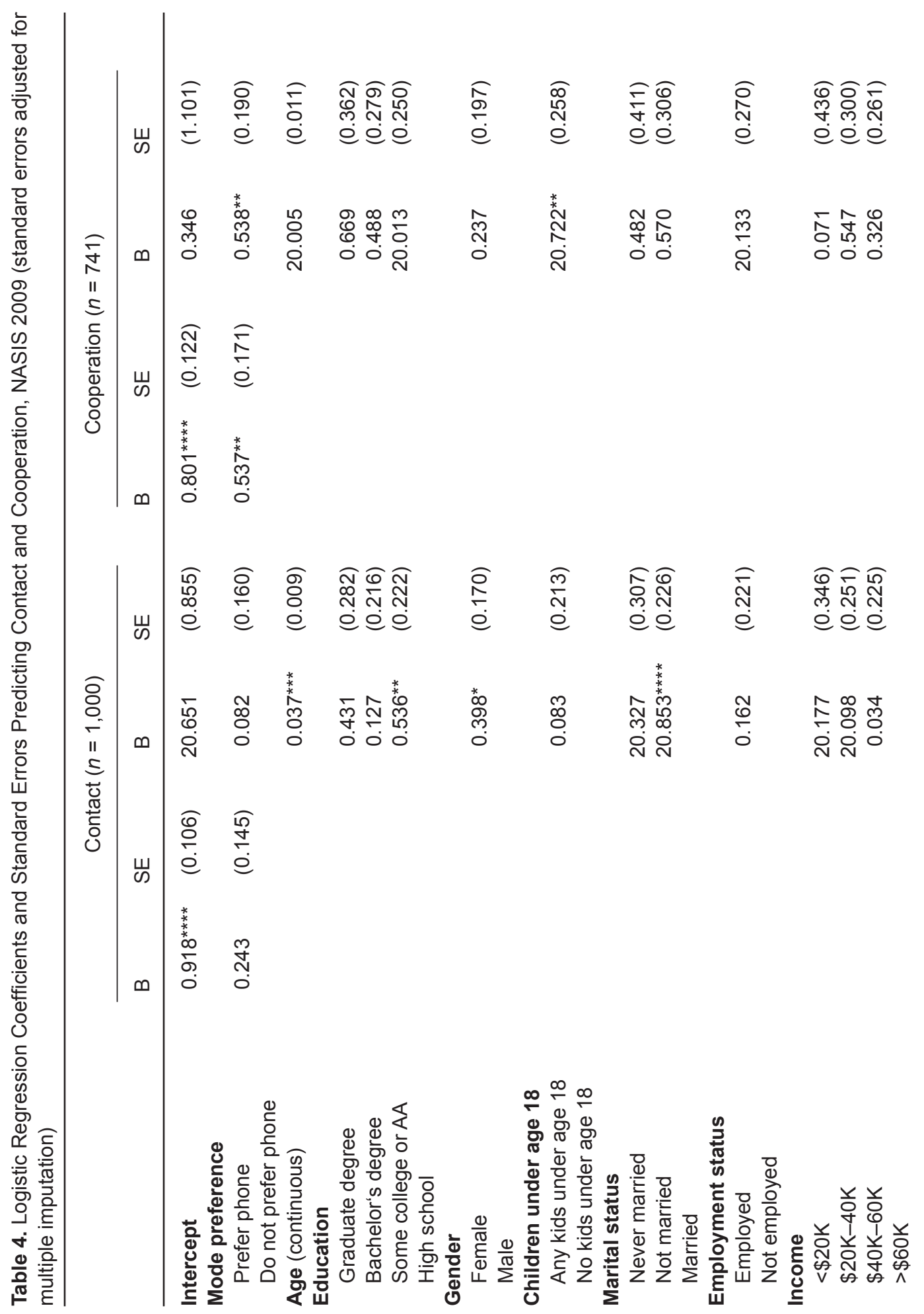




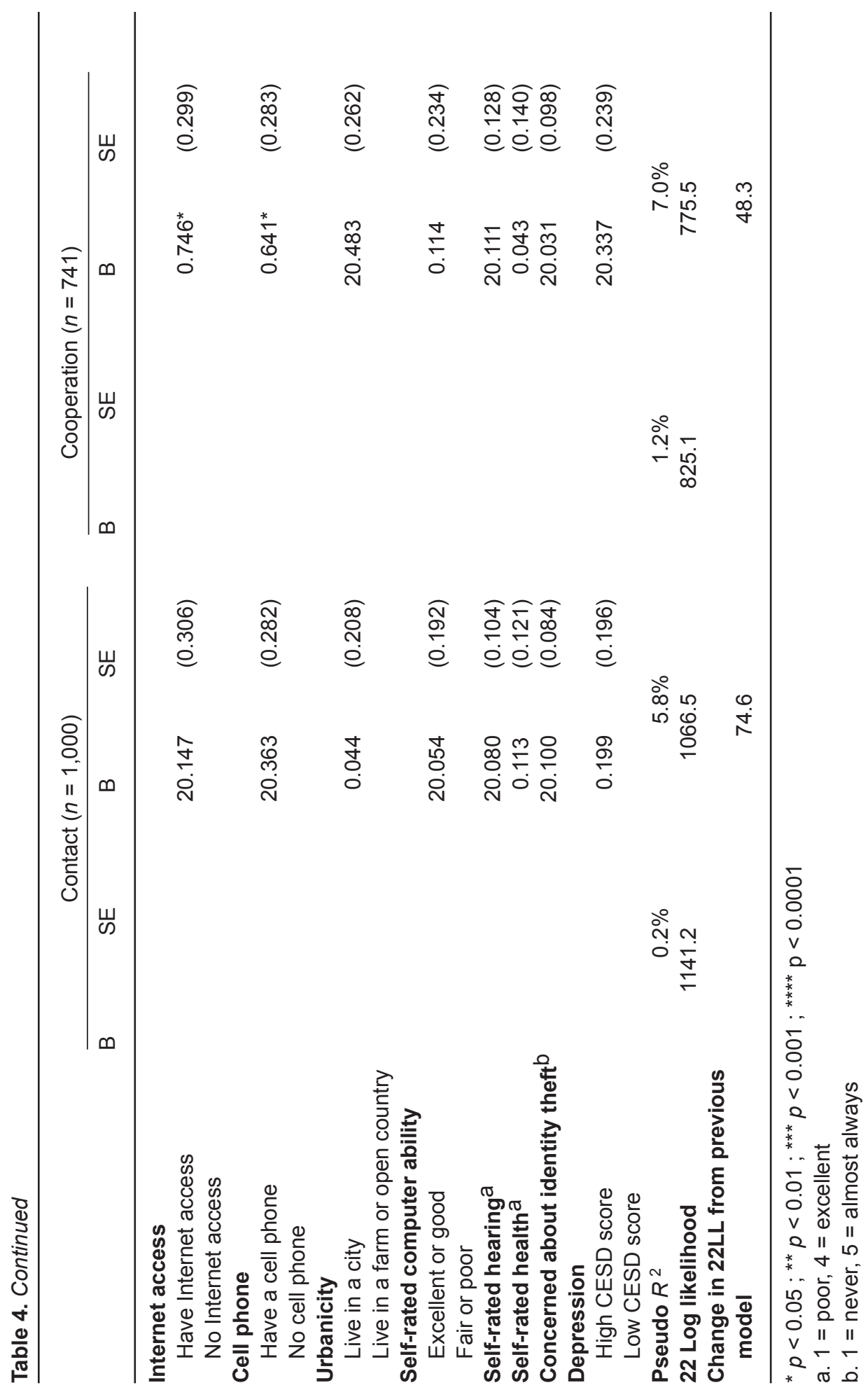


Table 5. Percent of Respondents Who Responded by Web by Self-Administered Mode Condition, Overall and Respondents with Internet Access, QLCN

\begin{tabular}{lcccc}
\hline & Mail only & Web only & $\begin{array}{c}\text { Mail then } \\
\text { Web }\end{array}$ & $\begin{array}{r}\text { Web then } \\
\text { Mail }\end{array}$ \\
& & & & \\
All respondents & & & 2.6 & 36.2 \\
$\quad$ Overall & 0.0 & 81.1 & 4.3 & 55.6 \\
Prefer Web & 0.0 & 100.0 & 3.7 & 36.1 \\
Prefer mail & 0.0 & 76.9 & 1.9 & 29.7 \\
Prefer interviewer-administered & 0.0 & 68.5 & 156 & 173 \\
$N$ & 159 & 72 & 0.63 & 7.66 \\
Chi-square & $\mathrm{n} / \mathrm{a}$ & 9.11 & .73 & .02 \\
$P$-value (2 d.f.) & & .01 & & \\
Respondents with Internet access & & & 2.8 & 40.7 \\
Overall & 0.0 & 87.9 & 4.4 & 55.6 \\
Prefer Web & 0.0 & 100.0 & 3.7 & 46.4 \\
Prefer mail & 0.0 & 90.9 & 2.2 & 32.6 \\
Prefer interviewer-administered & 0.0 & 77.4 & 142 & 150 \\
$N$ & 135 & 66 & 0.41 & 6.04 \\
Chi-square & $\mathrm{n} / \mathrm{a}$ & 6.59 & 0.81 & 0.049 \\
$P$-value (2 d.f.) & & 0.04 & & \\
\hline
\end{tabular}

Overall chi-square $=246.85,3$ d.f., $p<.0001$; persons who failed to report a mode preference are excluded from these analyses.

Only treatment, there is an overall significant association between mode preference and timing $\left(\chi^{2}(2)=8.47, p=0.01\right)$. As shown in Figure 2, about 28 percent of persons who preferred Web participated before the second questionnaire and an additional 12 percent participated after the second mailing, compared to 15 percent before and 6 percent after the second mailing among those who did not prefer Web surveys. Persons who preferred Web surveys participated after 12.8 days, on average, compared to 17.9 days for those who did not prefer Web surveys, a non-statistically significant difference of 5.1 days $(t=$ 1.19 , n.s.). ${ }^{3}$

In the Phone Only treatment, we calculate the number of days in the field starting from the day of the first call attempt for the case. On average, people who preferred interviewer-administered modes were in the field for a total of 24.8 days, compared to 29.6 days for those who did not prefer interviewer-administered modes, a statistically significant difference of 4.8 days $(t=2.34, p<.05)$. We see a similar pattern for the total number of days in the field before completion when we focus only on completed cases (12.9 days vs. 14.6 days, difference $=1.7$ days, $t=0.33$, n.s.) and when separating days to con- 


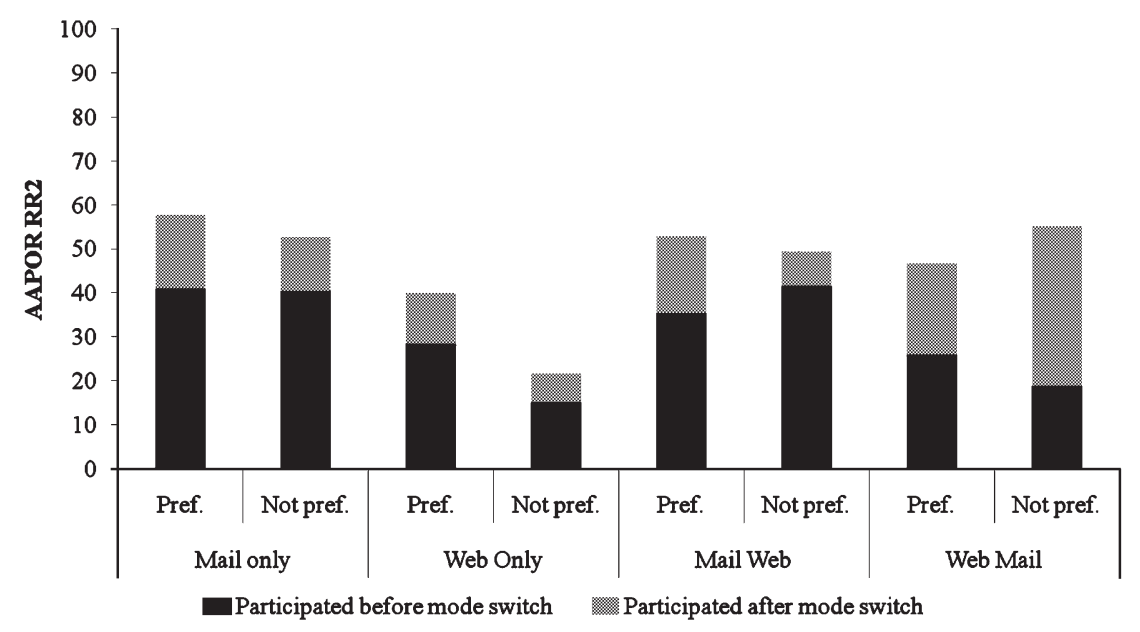

Figure 2. Cumulative Response Rates by Timing of Participation, QLCN.

tact and cooperation, but none of the differences are statistically significant (contact: difference $=4.06$ days, $t=0.42$, n.s.; cooperation: difference $=1.5$ days, $t=0.87$, n.s.).

Thus, among the single mode treatments, there is weak evidence in the Web and CATI modes that persons who receive the mode that they prefer participate faster than those who do not receive their preferred mode.

We now turn to the two mixed mode treatments. In the Mail then Web treatment, 35.3 percent of those who preferred mail participated after the first mailing, compared to 41 percent who did not prefer mail. After the mode switch, 17.7 percent of those who preferred mail participated, compared to about 8 percent who did not prefer mail. This distribution of participation by timing in the Mail then Web treatment was not significantly associated with mode preference at the conventional a $<.05$ levels $\left(\chi^{2}(2)=4.68, p=.096\right)$; there was also no difference in the number of days to completion (15.1 vs. 14.3 days, $t=$ 0.33 , n.s.).

In contrast, as with the Web Only treatment, we find significant associations between timing of participation and mode preference in the Web then Mail treatment $\left(\chi^{2}(2)=6.77\right.$, $p=0.03)$. Those who preferred the Web mode participated faster -26 percent participated before the mode switch, and 21 percent after the mode switch - than those who did not

3. If we examine the total number of recruitment attempts rather than timing and number of days in the field, we find no significant differences. In the self-administered modes, this arises partly by design — all persons received the advance letter and first questionnaire, almost all persons received the follow-up postcard, and all persons received the thank-you letter, with the main variability being receipt of the second questionnaire. Similarly, there is little difference in the effort exerted overall, before contact, or before completion for those who preferred interviewer-administered modes compared to those who preferred other modes in the telephone treatment. 
prefer Web surveys - 19 percent before the mode switch, and 36 percent after the mode switch. Those who preferred Web participated after 20.0 days, compared to 24.5 days for those who did not prefer the Web mode, but these estimates are not statistically different $(t$ $=1.56, p=0.12$ ). Thus, the support for $\mathrm{H} 4$ is mixed and weak.

\section{Discussion}

Mode preference has long been considered as a possible explanation for differences in survey participation across modes. We have shown through experimental evaluation that mode preference has some influence on survey participation, although it is not uniform across modes. In particular, as hypothesized in Hypothesis 1, preference for Web and phone modes predicts participation in those modes. Also as hypothesized, mode preference is related to cooperation, but not contactability, in telephone surveys. Mode preference is clearly related to mode choice when two modes are offered, at least among the mail and Web modes offered here. Finally, there is weak evidence that offering persons their preferred mode leads to slightly faster responses, although this is not consistent across modes.

Our study is limited by examining mode preference among previous study participants, but this is also a strength of the study. We have measured mode preference prior to the survey request of interest. Although evidence of which modes persons select when given a choice is indicative of preference for a particular mode, it also reflects familiarity, comfort, and perceptions of convenience with that communication medium, along with (sometimes) access to the communication medium itself. Disentangling these effects with prior measurement of mode preference necessitates a longitudinal design, since mode preference is not kept in administrative records or other information available from a frame. Importantly, we showed that mode preference matters even though these were previous phone cooperators willing to participate in future studies, perhaps attenuating the effect of mode preference. That is, persons who strongly preferred mail or Web modes may not have been adequately represented in the initial phone survey. If these persons had been recruited for the Web survey, the relationship between mode preference and participation in a preferred self-administered mode may have been even stronger.

There are sample composition differences among those who prefer interviewer-administered, mail, and Web surveys (Smyth, Olson, and Richards 2009). To the extent that these characteristics are available on a frame, these sample composition differences could be exploited to pre-assign a "likely" mode preference to a sampled person. For example, in a Web and mail survey, those who either have or are familiar with the Internet may be preassigned to a "likely" Web preference, whereas those who have poor computer skills could be pre-assigned to a "likely" mail preference. As such, resources could be targeted to make the survey benefits as salient as possible to the respondent. This approach would be perhaps most useful in a longitudinal survey where information is available on each sampled 
person prior to the survey request, but mode preference was not asked, and perhaps less useful in a general population survey with only addresses available on a frame (such as address-based samples drawn from the Delivery Sequence File; see Link et al. 2008).

Concerns about mode preference are most often voiced when conducting mixed mode self-administered surveys (Dillman et al. 2009; Millar and Dillman 2011). Although preference for Web surveys predicts participation and selection of that mode, it is notable that preference for telephone surveys also predicts participation in that mode. As such, those who conduct telephone surveys should be aware that persons who prefer the phone are more likely to participate than those who do not prefer phone surveys. Interestingly, there was no clear effect of mode preference for mail surveys - people who preferred phone or Web modes were just as likely to participate in a mail survey as those who preferred mail. As such, mail surveys appear to be robust to the effects of mode preference that we saw in the other modes.

Despite our evidence that those who prefer Web surveys participate at higher rates in them, offering a Web option along with a mail survey did not increase response rates over a mail survey alone for any mode preference. As such, programming a Web survey when it will be offered in conjunction with a mail survey may not be cost effective. Even if the Web survey is offered up front, the proportion of people who participated via the Web was small relative to those who participated by mail. Future studies could directly evaluate the costs of programming compared to incorporating other recruitment techniques - such as incentives or another mailing-for a mail-only study.

Although the effect of mode preference was statistically significant, it was small in magnitude and most prominent for Web surveys. This finding is especially important looking toward the future as the general public becomes more comfortable with the Internet (Zickuhr 2010). From one standpoint, as more people develop computer skills, the proportion of persons who prefer the Web as a survey mode may increase. Catering to a Web mode preference then may have a larger effect on response rates and response timing. Yet, the Web-only treatment had the lowest response rate overall. As such, offering only a Web survey, while appealing to those who prefer that mode, may lower overall response rates. Furthermore, as more people become Internet-savvy, reported preference for a Web survey may become more diffuse throughout the population, and lose its predictive ability for survey participation. Thus, the relationship between mode preference and survey participation should be intermittently reevaluated as characteristics that are correlates of mode preference change throughout the population.

Although we have some indication of differences in response rates for some modes, we have not yet examined how nonresponse bias properties of key statistics are affected by offering individuals their preferred mode. Since nonresponse rates are not necessarily indicative of nonresponse bias on key estimates (Groves 2006), this step will provide even greater insight into whether mode preference "matters." This examination will be part of future research. 


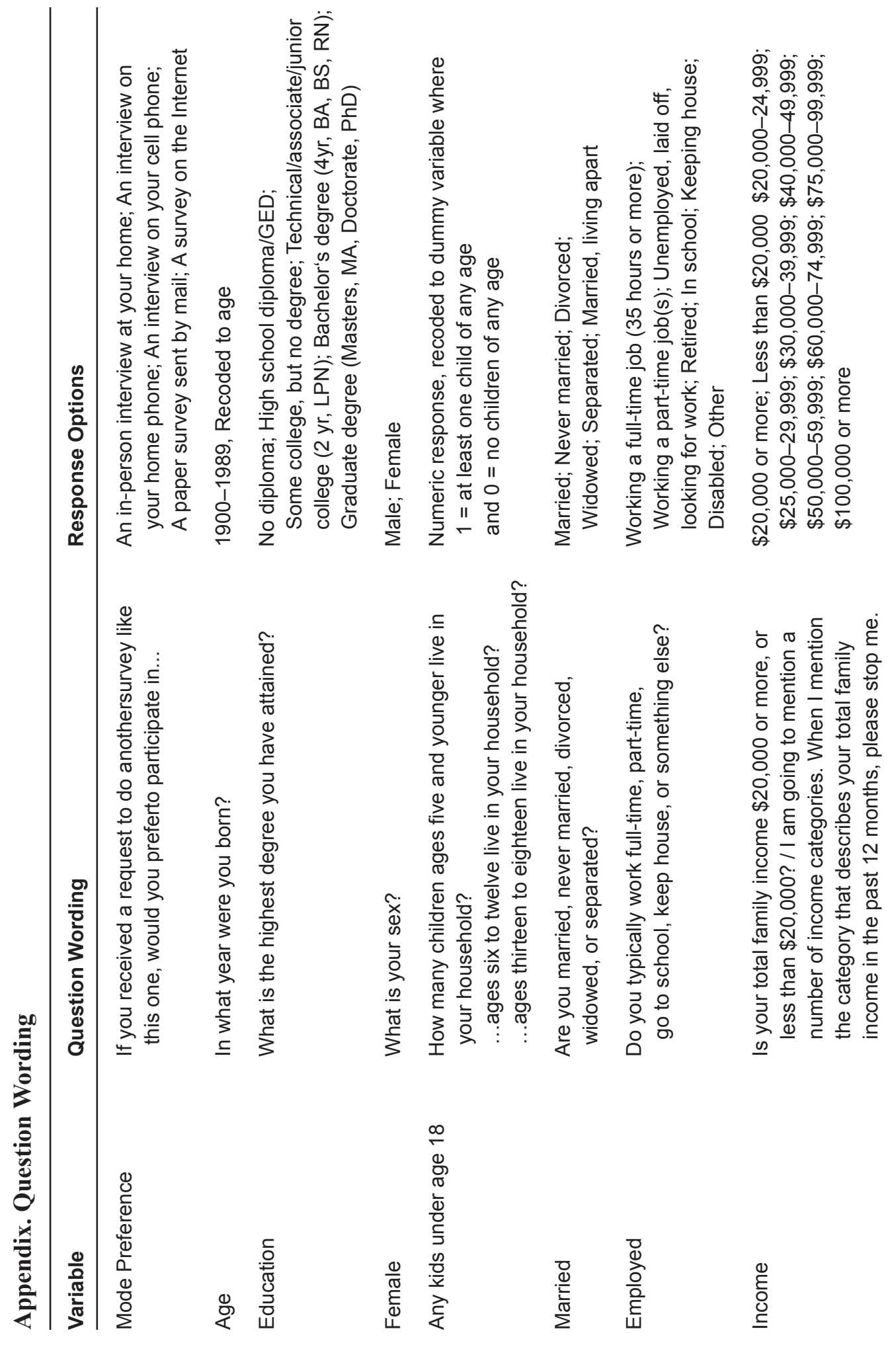




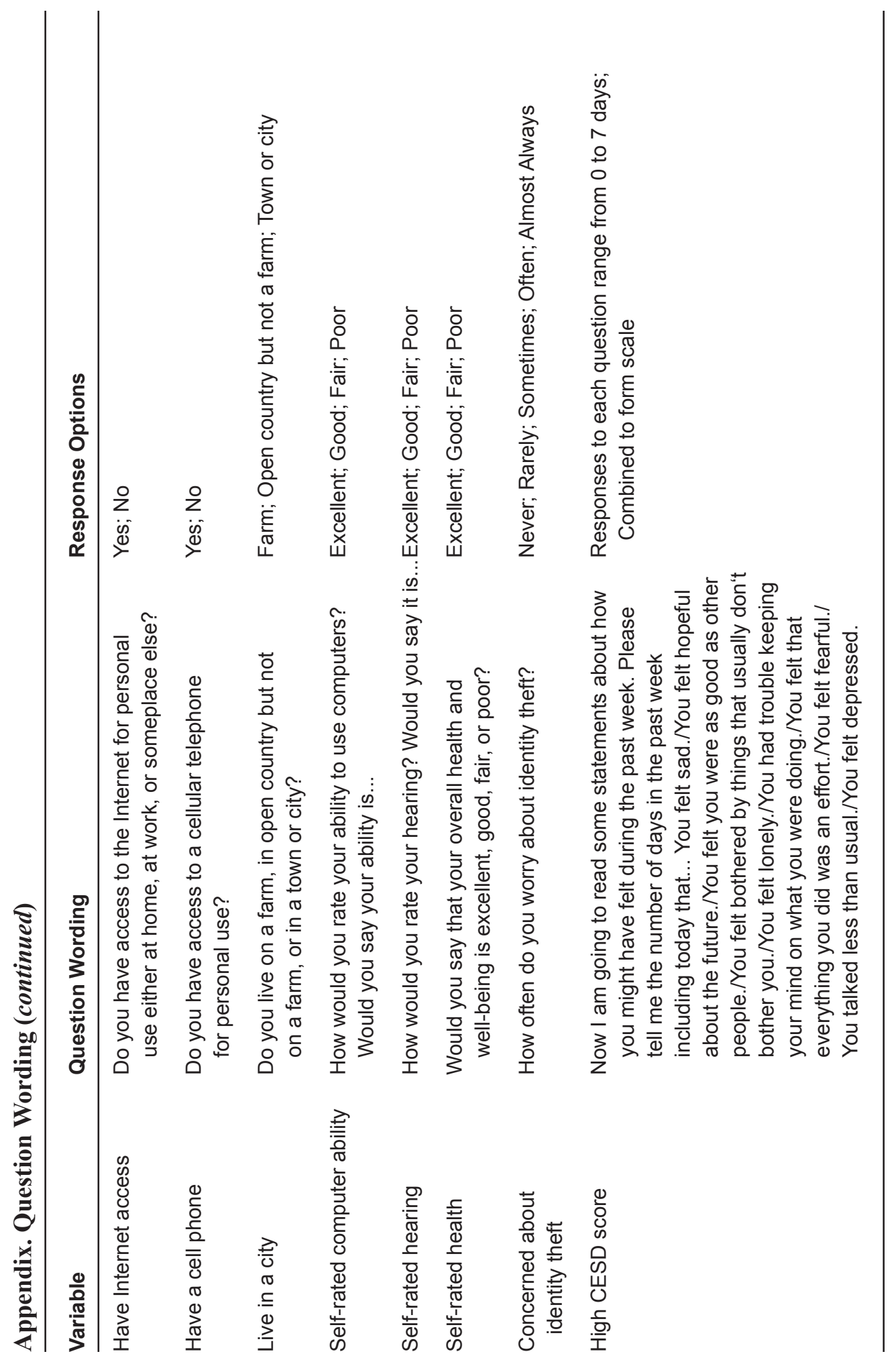




\section{References}

American Association for Public Opinion Research. 2011. Standard Definitions: Final Dispositions of Case Codes and Outcome Rates for Surveys. 7th ed. American Association for Public Opinion Research. http://www.aapor.org/Standard Definitions2.htm

Curtin, Richard, Stanley Presser, and Eleanor Singer. 2000. "The Effects of Response Rate Changes on the Index of Consumer Sentiment." Public Opinion Quarterly 64:413-28.

de Leeuw, Edith. 2005. "To Mix or Not to Mix Data Collection Modes in Surveys." Journal of Official Statistics 21:233-55.

de Leeuw, Edith, and Wim de Heer. 2002. "Trends in Household Survey Nonresponse: A Longitudinal and International Perspective.” In Survey Nonresponse, edited by Robert M. Groves, Don A. Dillman, John L. Eltinge, and Roderick J. A. Little, 41-54. New York: John Wiley \& Sons.

Denniston, Maxine, Kevin Stein, Frank Baker, Donna Brogan, Michele West, and Lisa Roche. 2000. "An Experiment in Data Collection Mode Preference of Long-Term Cancer Survivors." Proceedings of Survey Research Methods Section of the American Statistical Association: 411-16.

Dillman, Don A., Glenn Phelps, Robert Tortora, Karen Swift, Julie Kohrell, Jodi Berck and Benjamin L. Messer. 2009. "Response Rate and Measurement Differences in Mixed Mode Surveys Using Mail, Telephone, Interactive Voice Response (IVR), and the Internet." Social Science Research 38:1-18.

Dillman, Don A., Jolene D. Smyth and Leah Melani Christian. 2009. Internet, Mail, and Mixed Mode Surveys: The Tailored Design Method. 3rd ed. Hoboken, NJ: John Wiley \& Sons.

Dillman, Don A., and John Tarnai. 1988. “Administrative Issues in Mixed Mode Surveys.” In Telephone Survey Methodology, edited by Robert M. Groves, Paul Biemer, Lars Lyberg, James T. Massey, William L. Nicholls II, and Joseph Waksberg, 509-28. New York: John Wiley \& Sons.

Dillman, Don A., Kirsten K. West, and Jon R. Clark. 1994. "Influence of an Invitation to Answer by Telephone on Response to Census Questionnaires." Public Opinion Quarterly 58:557-68.

Diment, Kieren, and Sam Garrett-Jones. 2007. "How Demographic Characteristics Affect Mode Preference in a Postal/Web Mixed Mode Survey of Australian Researchers." Social Science Computer Review 25:410-17.

Gesell, Sabina B., Maxwell Drain, and Michael P. Sullivan. 2007. "Test of a Web and Paper Employee Satisfaction Survey: Comparison of Respondents and Non-Respondents." International Journal of Internet Science 2:45-58.

Gilbert, Tim. 2009. "Mode Preferences in the 2008 National Survey of College Graduates." Paper presented at the Annual Meeting of the American Association of Public Opinion Research, Hollywood, FL.

Groves, Robert M. 2006. "Nonresponse Rates and Nonresponse Bias in Household Surveys.” Public Opinion Quarterly 70:646-75.

Groves, Robert M., and Robert L. Kahn. 1979. Surveys by Telephone. New York: John Wiley \& Sons.

Groves, Robert M., Eleanor Singer, and Amy Corning. 2000. "Leverage-Saliency Theory of Survey Participation: Description and an Illustration.” Public Opinion Quarterly 64:299-308.

Kaplowitz, Michael D., Timothy D. Hadlock, and Ralph Levine. 2004. "A Comparison of Web and Mail Survey Response Rates." Public Opinion Quarterly 68:94-101.

Levenstein, Rachel. 2009. "Mode Preference, Mode Choice, and Data Quality in the Army De- 
fense, Resilience, and Retention Study." Paper presented at the Annual Meeting of the American Association for Public Opinion Research, Hollywood, FL.

Link, Michael W., Michael P. Battaglia, Martin R. Frankel, Larry Osborn, and Ali H. Mokdad. 2008. "A Comparison of Address-Based Sampling (ABS) versus Random-Digit Dialing (RDD) for General Population Surveys.” Public Opinion Quarterly 72:6-27.

Millar, Morgan M., and Don A. Dillman. 2011. "Improving Response to Web and Mixed Mode Surveys.” Public Opinion Quarterly 75:249-69.

Millar, Morgan M., Allison C. O’Neill, and Don A. Dillman. 2009. “Are Mode Preferences Real?” Technical Report 09-003. Pullman, WA: Social \& Economic Sciences Research Center, Washington State University.

Miller, Thomas I., Michelle Miller-Kobayashi, Erin Caldwell, Sarah Thurston, and Ben Collett. 2002. "Citizen Surveys on the Web: General Population Surveys of Community Opinion." Social Science Computer Review 20:124-36.

NSF. 2008. "Survey of Doctorate Recipients Survey Description.” National Science Foundation.

Olson, Kristen, and Robert M. Groves. Forthcoming. "An Examination of Within-Person Variation in Response Propensity over the Data-Collection Field Period." Journal of Official Statistics. http://www.nsf.gov/statistics/srvydoctoratework/

Raghunathan, Trivellore E., James M, Lepkowski, John Van Hoewyk, and Peter Solenberger. 2001. "A Multivariate Technique for Multiply Imputing Missing Values Using a Sequence of Regression Models." Survey Methodology 27:85-95.

Ryan, Judy M., John R. Corry, Robyn Attewell, and Michael J. Smithson. 2002. "A Comparison of an Electronic Version of the SF-36 General Health Questionnaire to the Standard Paper Version." Quality of Life Research 11:19-26.

Schaefer, David R., and Don A. Dillman. 1998. "Development of a Standard E-Mail Methodology: Results of an Experiment." Public Opinion Quarterly 62:378-97.

Selfa, Lance, and Scott Sederstrom. 2006. "Respondent Mode Preference in a Multi-Mode Survey." Paper presented at the Annual Meeting of the American Association for Public Opinion Research, Montreal, Quebec, Canada.

Shih, Tse-Hua, and Xitao Fan. 2002. "Response Rates and Mode Preferences in Web-Mail Mixed Mode Surveys: A Meta-Analysis." International Journal of Internet Science 2:59-82.

Smyth, Jolene D., Kristen Olson, and Ashley Richards. 2009. “Are Mode Preferences Real?” Paper presented at the Annual Meeting of the American Association for Public Opinion Research, Hollywood, Florida.

Tarnai, John, and M. Chris Paxson. 2004. "Survey Mode Preferences of Business Respondents." Proceedings of Survey Research Methods Section of the American Statistical Association: 4898-904.

Vehovar, Vasja, Zenel Batagelj, Katja Lozar Manfreda, and Metka Zalatel. 2002. "Nonresponse in Web Surveys." In Survey Nonresponse, edited by Robert M. Groves, Don A. Dillman, John L. Eltinge, and Roderick J. A. Little, 229-42. New York: John Wiley and Sons. 